Research Paper

\title{
Corrugated stainless-steel mesh as a simple engineerable electrode module in bio-electrochemical system: Hydrodynamics and the effects on decolorization performance
}

\author{
Hong-Cheng Wang ${ }^{a, b}$, Hao-Yi Cheng ${ }^{a, *}$, Dan Cui ${ }^{a}$, Bo Zhang ${ }^{a}$, Shu-Sen Wang ${ }^{a, b}$, \\ Jing-Long Han ${ }^{\mathrm{a}, \mathrm{b}}$, Shi-Gang Su ${ }^{\mathrm{a}, \mathrm{b}}$, Rui Chen ${ }^{\mathrm{c}}, \mathrm{Ai}-\mathrm{Jie}$ Wang ${ }^{\mathrm{a}, \mathrm{b}, \mathrm{c}, *}$ \\ a Key Laboratory of Environmental Biotechnology, Research Center for Eco-Environmental Sciences, Chinese Academy of Sciences, Beijing 100085, PR China \\ ${ }^{\mathrm{b}}$ University of Chinese Academy of Sciences, Beijing, 100049, PR China \\ c State Key Laboratory of Urban Water Resource and Environment, Harbin Institute of Technology (SKLUWRE, HIT), Harbin 150090, PR China
}

\section{H I G H L I G H T S}

- A cost-effective and engineerable electrode module for BES was developed. - Decolorization significantly
increased by designing electrode as the corrugated type.

- $c$-SMEM was found to improve the hydrodynamics condition in BES.

- Economic analysis was carried out and compared with conventional anaerobic system.

\section{A R T I C L E I N F O}

\section{Article history:}

Received 13 March 2017

Received in revised form 12 May 2017

Accepted 24 May 2017

Available online 27 May 2017

\section{Keywords:}

Bio-electrochemical system

Stainless-steel mesh electrode

Corrugated configuration

Hydrodynamic

Engineerable
G R A P H I C A L A B S T R A C T
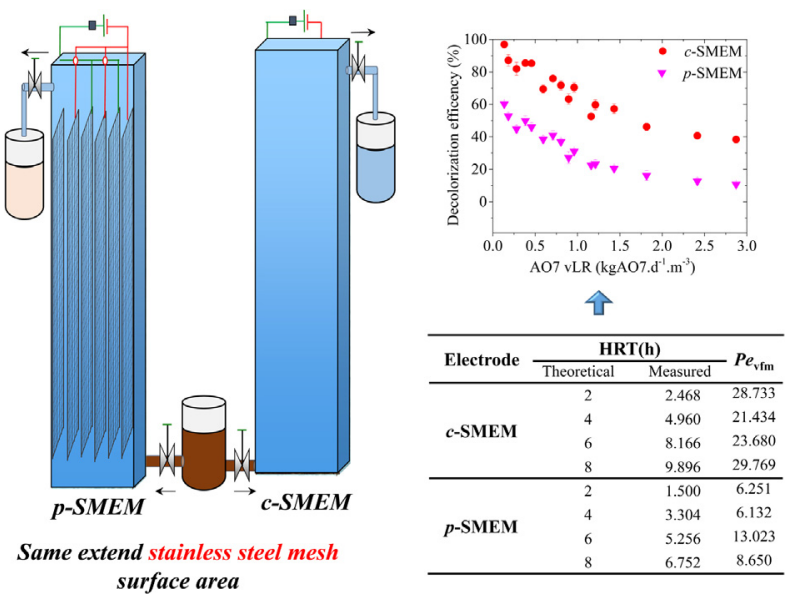

\begin{abstract}
A B S T R A C T
The application of bio-electrochemical system (BESs) is strongly depended on the development of the engineering applicable electrode. Here we described an economical and readily processable electrode module with three-dimensional structure, the corrugated stainless-steel mesh electrode module ( $c$ SMEM). This novel developed electrode module was demonstrated to provide a good hydrodynamic characteristic and significantly enhanced the decolorization performance of the BES when serving for treating azo dye (acid orange 7, AO7) containing wastewater. Compared to the conventional planar electrodes module ( $p$-SMEM), $c$-SMEM was found to prolong the mean residence time $\left(\mathrm{MRT}_{\theta}\right)$ of AO7 and change the flow pattern closer to the plug flow. As a result, the maximum enhancement of the volumetric decolorization rate (vDR) can reach to $255 \%$, even when the $c$-SMEM and $p$-SMEM have the same electrode surface area. In addition, a techno-economic analysis model was established to elucidated the effects of the decolorization performance and the material cost on the initial capital cost, which revealed the BES
\end{abstract}

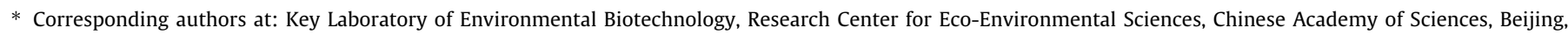
100085, PR China.

E-mail addresses: chenghaoyihit@126.com (H.-Y. Cheng), ajwang@rcees.ac.cn (A.-J. Wang).
} 
with c-SMEM could be economically comparable to or even better than the traditional bio-decolorization technologies. These results suggest $c$-SMEM holds great potential for engineering application, which may help paving the way of applying BES at large-scale.

(C) 2017 Published by Elsevier B.V.

\section{Introduction}

Bio-electrochemical systems (BESs) have been explored extensively for its innovative features and environmental benefits for the degradation of a number of recalcitrant contaminants [1,2], such as azo dyes [3-5], nitro-aromatics [6-8], and halogenated aromatics [9]. Although the BESs commonly shows a superior performance compared to the traditional biological processes, this technology is still far away from the full-scale application, which especially suffers from the high capital cost as well as the scaling-up of the electrode $[2,10,11]$. In general, the engineerable electrode for BESs in wastewater treatment is expected to having the features including low cost, good flow regime, large specific surface area, excellent mechanical strength, high conductivity, good biocompatibility and strong chemical stability [11-14].

In past decades, various carbon-based electrodes with three dimensional (3D) configuration were developed in BESs, such as carbon brush, packed graphite granules, reticulated vitreous carbon, etc. [15-25]. Since these 3D electrodes provide higher ratio of the electrode surface area to the reactor working volume compared to the two dimensional electrode, the significant improvements were observed in the BESs for implementing diverse functions [26,27]. However, in case of the application at large-scale, carbon-based electrodes are likely limited by the low conductivity and poor process-ability $[11,28]$. In addition, although carbon based electrode were considered as cost-effective, those estimations were often just carried out according to the costs of the materials yet overlooked the costs of labor and other consumptions during the electrode processing. As the manufacture of these 3D carbon-based electrodes lacks matured industrial chains, the cost of the later could be even higher than the materials. As a comparison, metal-based materials, such as gold, silver, copper, nickel and stainless-steel, possess better physical characteristics in particular of the good conductivity and easy machining. In addition, many types of metal-based electrodes are capable of cultivating well-performing electrochemically active biofilms, which further highlights their application potential [22,29,30]. There into, stainless-steel is regarded as the most suitable material for scaling-up due to the low capital cost and relative stable chemical properties [31-33]. In order to increase the electrode surface area in the reactor, some stainless-steel based electrodes with 3D configuration were also reported in BES studies, such as stainless-steel foam [32], binder-free carbon black/stainless-steel mesh [33] and stainless-steel ball [34].

In addition to gaining higher ratio of the electrode surface area to the reactor working volume, the improvement of hydrodynamics has been recently revealed in the BESs with 3D designed carbon electrodes [35-37]. A good hydraulic flow regime was suggested to prolong the residence time [35], balance the phase distribution, prevent excessive growth of sludge or biofilm [38] and consequently enhance the reactor performance [37]. Particularly, the hydrodynamic improvement was reported by simply changing the design of electrode other than increasing the usage of electrode material. This would be very helpful to developing the engineerable electrode module economically. Yet the effects of 3D design of stainless-steel based electrodes on the hydraulic flow regime in BES have not been investigated.
Azo dyes are the most widely used dyestuffs in textiles, leathers, plastics, cosmetics, and food industry $[39,40]$. The biodegradation of azo dye is generally difficult under aerobic condition, which can be facilitated after a prior reduction step to forming the corresponding color-less aromatic amines [39,41]. Thus, the strategy for biodegradation of azo dyes commonly combines an anaerobic process with a followed aerobic process. The significant enhancement of azo dye decolorization, compared to the conventional anaerobic process, has been extensively reported in BES $[42,43]$. However, the involved electrodes, such as carbon brush and graphite granules, likely suffer from a big gap for engineering application as the concerns mentioned above.

In this study, we offered a facile and efficient approach to design the BES electrodes as the 3D type, where the cost-effective stainless-steel meshes were simply folded as the corrugated configuration and assembled as the electrode module. As the manufacture of stainless steel mesh and the folding process are capable of automatically machining at large-scale, this corrugated stainless-steel mesh electrode module ( $c$-SMEM) holds great potential for the engineering application. The decolorization performance of the $c$-SMEM equipped BES ( BES $_{c \text {-SMEM }}$ ) was tested by using the acid orange 7 (AO7) as a mode azo dye under three different folding angle conditions. Electrode module assembled by conventional planar steel mesh ( $\mathrm{p}-\mathrm{SMEM}$ ) was employed as the control. In addition, residence time distribution (RTD) analysis was conducted to explore the effect of the corrugated configuration on the flow regime in BES. The correlations of the hydrodynamics to the decolorization performance were discussed. Moreover, a decolorization rate dependent techno-economical assessment model was established. At certain decolorization efficiency, this model can offer us a tool to compare the initial capital cost of the BESc-SMEM with the conventional anaerobic process as well as to understand the economically preferred folding angle of the c-SMEM.

\section{Methods and materials}

\subsection{BES construction, inoculation and operation}

\section{Corrugated electrode module preparation}

The SAE 304 stainless-steel meshes ( 50 grids per inch, containing $\mathrm{Cr}$ and $\mathrm{Ni}$ with average weight of $19 \%$ and $9 \%$, respectively) was used as electrode material, which was folded to corrugated shape with three different angles $\left(20^{\circ}, 40^{\circ}\right.$ and $\left.60^{\circ}\right)$. Subsequently, two pieces of corrugated stainless-steel meshes were assembled together with the vertical distance of $2 \mathrm{~mm}$ as the $c$-SMEM, which served as the cathode and the anode, respectively (Fig. 1 \& Table 1 ). As the control, the $p$-SMEM was constructed by six pieces of stainless-steel meshes without corrugation, which has the same surface area as the $c$-SMEM with the folding anger of $40^{\circ}$, each pieces of $p$-SMEM also kept the vertical distance of $2 \mathrm{~mm}$. In prior to the experiment, the electrode modules were thoroughly treated in $1 \mathrm{M} \mathrm{H}_{2} \mathrm{SO}_{4}$ for $24 \mathrm{~h}$ and then washed by the deionized water.

\section{BES reactor}

Four plexiglas cuboid-type reactors was designed to guarantee wastewater penetrating the electrode module (Fig. 1 \& Table 1). The reactors equipped with three types of $c$-SMEM (with the fold- 


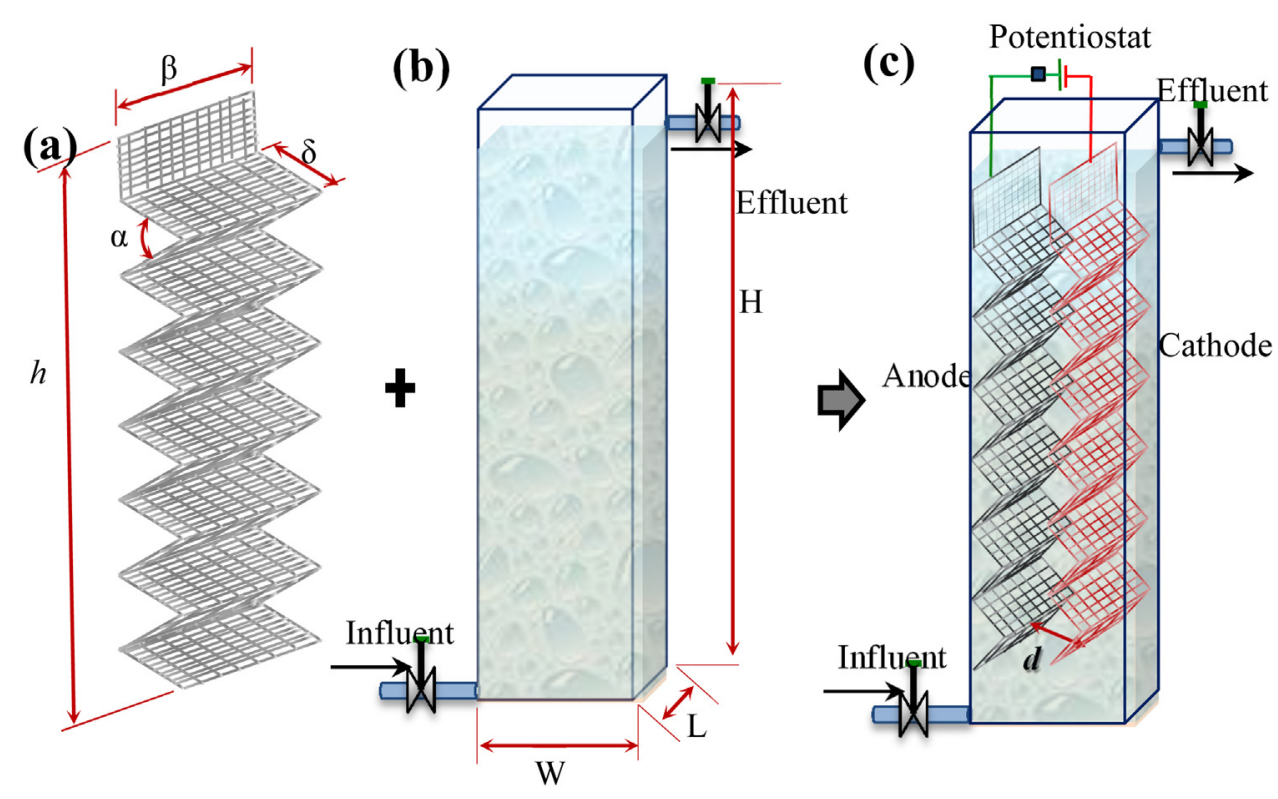

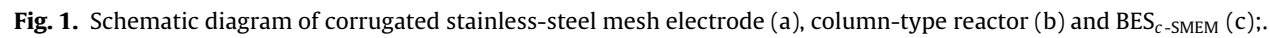

Table 1

Summary of the different configurations of the electrode modules and the reactors.

\begin{tabular}{|c|c|c|c|c|c|c|c|}
\hline No. & Reactor & $\alpha\left({ }^{\circ}\right)$ & $\begin{array}{l}\beta \\
(\mathrm{mm})\end{array}$ & $\begin{array}{l}\delta \\
(\mathrm{mm})\end{array}$ & $\begin{array}{l}\mathrm{h} \\
(\mathrm{mm})\end{array}$ & $\begin{array}{l}\text { Surface } \\
\text { area }^{a} / \mathrm{m}^{2}\end{array}$ & $\begin{array}{l}\text { Reactor size } \\
(\mathrm{L} \times \mathrm{W} \times \mathrm{H}) / \mathrm{mm}\end{array}$ \\
\hline 1 & $\mathrm{R}_{\alpha 20}$ & 20 & 70 & 30 & 500 & 0.201 & $70 \times 30 \times 550$ \\
\hline 2 & $\mathrm{R}_{\alpha 40}$ & 40 & 70 & 30 & 500 & 0.105 & $70 \times 30 \times 550$ \\
\hline 3 & $\mathrm{R}_{\alpha 60}$ & 60 & 70 & 30 & 500 & 0.067 & $70 \times 30 \times 550$ \\
\hline 4 & $\mathrm{R}_{180}$ & 180 & 1 & 1 & 1 & 0.105 & $70 \times 30 \times 550$ \\
\hline
\end{tabular}

a Surface area represents the area of anode extended to signal layer stainless-steel mesh.

ing angels of $20^{\circ}, 40^{\circ}$ and $60^{\circ}$ ) were denoted as $R_{\alpha 20}, R_{\alpha 40}$ and $\mathrm{R}_{\alpha 60}$, while that equipped with $p$-SMEM was denoted as $\mathrm{R}_{\alpha 180}$. An $\mathrm{Ag} / \mathrm{AgCl}$ reference electrode (+197 $\mathrm{mV}$ vs standard hydrogen electrode, Beijing Union Trust Co., Ltd., China) was installed between the anode and the cathode to enable potential measurement. An external resistor $\left(R_{\mathrm{ex}}\right)$ of $10 \Omega$ was connected in the circuit as the current sampler. The voltage across the $R_{\mathrm{ex}}$, the cathode potential and anode potential were recorded every $10 \mathrm{~min}$ by a data acquisition system (Keithley 2700, Keithley Co., Ltd., USA).

\section{Inoculation and Operation}

Each reactor was inoculated with $10 \mathrm{~mL}$ concentrated anaerobic sludge from a BES that had been operated over 200 days [44]. Domestic wastewater (with average COD of $400 \mathrm{mg} / \mathrm{L}$, average ammonium of $58 \mathrm{mg} / \mathrm{L}$ ) collected from a storage tank of a housing estate (Haidian, Beijing) was amended with $50 \mathrm{mg} \mathrm{l}^{-1} \mathrm{AO7}$ and continuously fed into the reactors through the peristaltic pump (BT100-1L, Longer Co., China). 0.5 V was applied across the anode and the cathode during the whole experiments by a DC power (PS3005D, Zhaoxin Co., Ltd., China). After the BESs were started up, the decolorization performance of the BESs were investigated at a series of AO7 volumetric loading rates (vLRs, between 0.135 and $\left.2.873 \mathrm{kgAO} 7 \mathrm{~m}^{-3} \mathrm{~d}^{-1}\right)$ by altered the influent concentration (50, 100, 150, 200 and $240 \mathrm{mg} \mathrm{l}^{-1}$ ) or the theoretical HRT (tHRT, 2, 4, 6 and $8 \mathrm{~h}$ ). All of the experiments mentioned above were performed at room temperature $\left(24 \sim 29^{\circ} \mathrm{C}\right)$.

\subsection{Analysis and calculations}

Liquid samples taken from the BESs were filtered through the $0.45 \mu \mathrm{m}$ membrane filters. AO7 concentration was determined by
UV-vis spectrophotometer at the wavelength of $484 \mathrm{~nm}$ [3]. The morphology of biofilms was examined using a field emission scanning electron microscope (FE-SEM) (SU8000, Hitachi UHR, Japan) after the pretreatment as described in Wang et al. [45]. The current $(\mathrm{mA})$ was obtained based on the detected voltage across the sampling resistor according to the Ohm's law. The decolorization efficiency (DE, \%) and the volumetric decolorization rates (vDRs, $\mathrm{kgAO} 7 \mathrm{~m}^{-3} \mathrm{~d}^{-1}$ ) were calculated according to Cui et al. [46].

\subsection{Hydrodynamics test and modelling}

Residence time distribution (RTD) analysis was performed according to the stimulus-response method by using AO7 as the tracer because it is easy to determine and it also represents the actual flow state in BES reactor $[47,48]$. The tHRT of the tracer were set as 2, 4, 6 and $8 \mathrm{~h}$, respectively. The recovery of the tracer was confirmed to be more than $90 \%$ in all experiments. The exit age-distribution function $(E(\theta))$ was used to analyze the flow pattern, while the normalized mean residence time $\left(\mathrm{MRT}_{\theta}\right)$ was used to characterize the measured HRTs of the BESs. The square of the standard deviation $\left(\sigma_{\theta}^{2}\right)$ was used to characterize the degree of back-mixing in the BESs. To further explore the hydrodynamic properties of these BESs with different electrode module configuration, four hydraulic models (tanks-in-series model (TIS), longitudinal dispersion model (LD), modified TIS model (mTIS) and modified longitudinal dispersion model ( $\mathrm{mLD})$ ) were established in this study. The details of RTD analysis and model development were described in the Supporting Material (SM). 


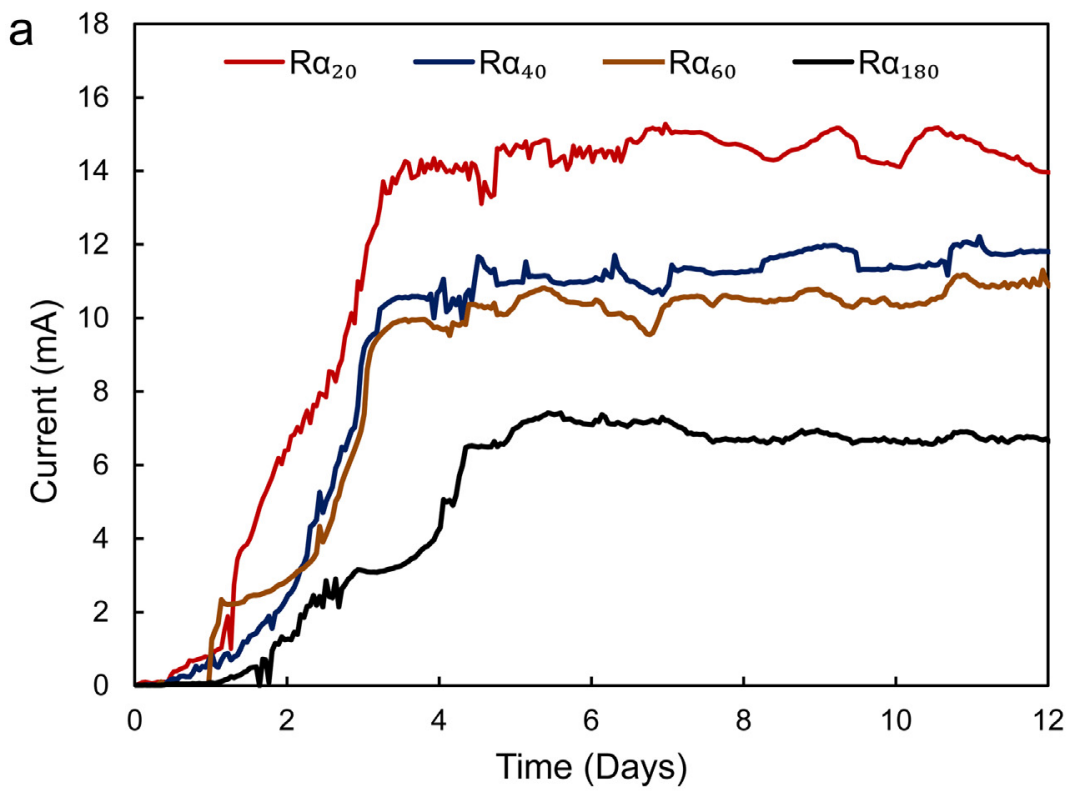

b
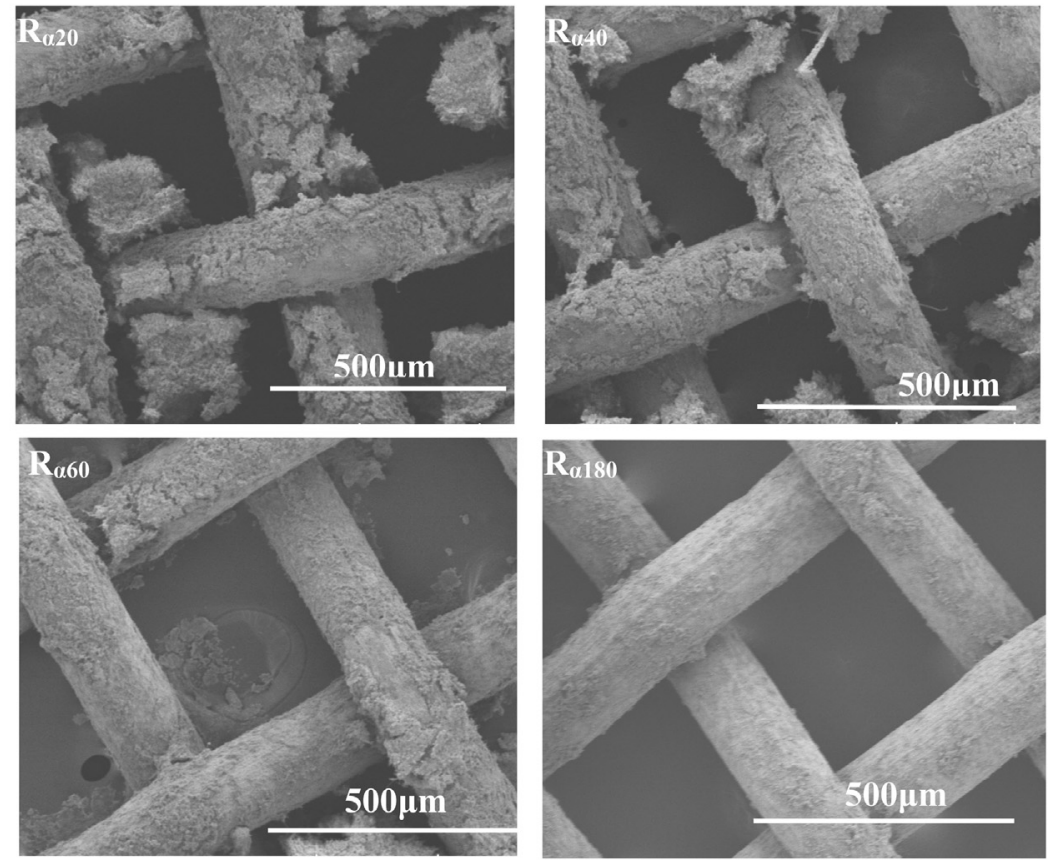

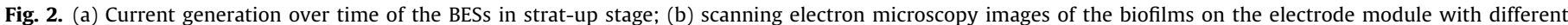
configurations;

\section{Results}

\subsection{Start-up}

During the start-up period, four BES reactors were operated with AO7 loading rate at $0.15 \mathrm{kgAO}^{-3} \mathrm{~m}^{-1}$. As shown in Fig. 2, current output was observed in all reactors in 2 days and finally got to the plateau after going through a rising duration. The startup of the $B S_{C-S M E M}\left(R_{\alpha 20}, R_{\alpha 40}\right.$ and $\left.R_{\alpha 60}\right)$ was faster than that of $\mathrm{BES}_{p \text {-SMEM }}\left(\mathrm{R}_{\alpha 180}\right)$, which spent about 3 days to establish a stable status, while the later required 2 more days. In addition, $\mathrm{BES}_{c \text {-SMEM }}$

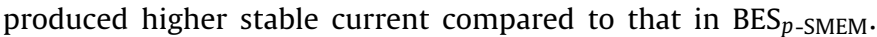
Among different $c$-SMEM equipped BESs, $\mathrm{R}_{\alpha 20}$ showed the highest stable current output ( $14.08 \pm 0.16 \mathrm{~mA})$, which was about $33 \%$ and $43 \%$ higher than that observed in $R_{\alpha 40}$ and $R_{\alpha 60}$, respectively. Moreover, the SEM images (Fig. 2b) obtained on day 12 showed that more biofilm attached on the $c$-SMEM, indicating the $c$-SMEM facilitated the microbial growth.

\subsection{BESs performance under various AO7 volumetric loading rates ( $v L R s$ )}

With increasing the AO7 vLRs, DEs of all reactors gradually decreased (Fig. 3a) while the vDRs showed an increase trend (Fig. 3b). Compared to the $\mathrm{BES}_{p \text {-SMEM }}$, DEs of the $\mathrm{BES}_{c \text {-SMEM }}$ were at least 1.5 times higher at all AO7 vLRs. vDRs were also shown to be superior in $\mathrm{BES}_{C \text {-SMEM }}$, especially at higher AO7 vLRs. When the AO7 vLRs over $1 \mathrm{kgAO} 7 \mathrm{~m}^{-3} \mathrm{~d}^{-1}$, the vDRs change in $\mathrm{BES}_{p-S M E M}$ became smooth while the vDRs kept increasing in $\mathrm{BES}_{c-S M E M}$. This result indicates $\mathrm{BES}_{p \text {-SMEM }}$ has reached to its maximum decolorization capacity (with the vDRs of around $0.71 \mathrm{kgAO}^{-3} \mathrm{~m}^{-1}$ ) but $\mathrm{BES}_{c-S M E M}$ still fall into the AO7 loading rate control stage. Among 
a
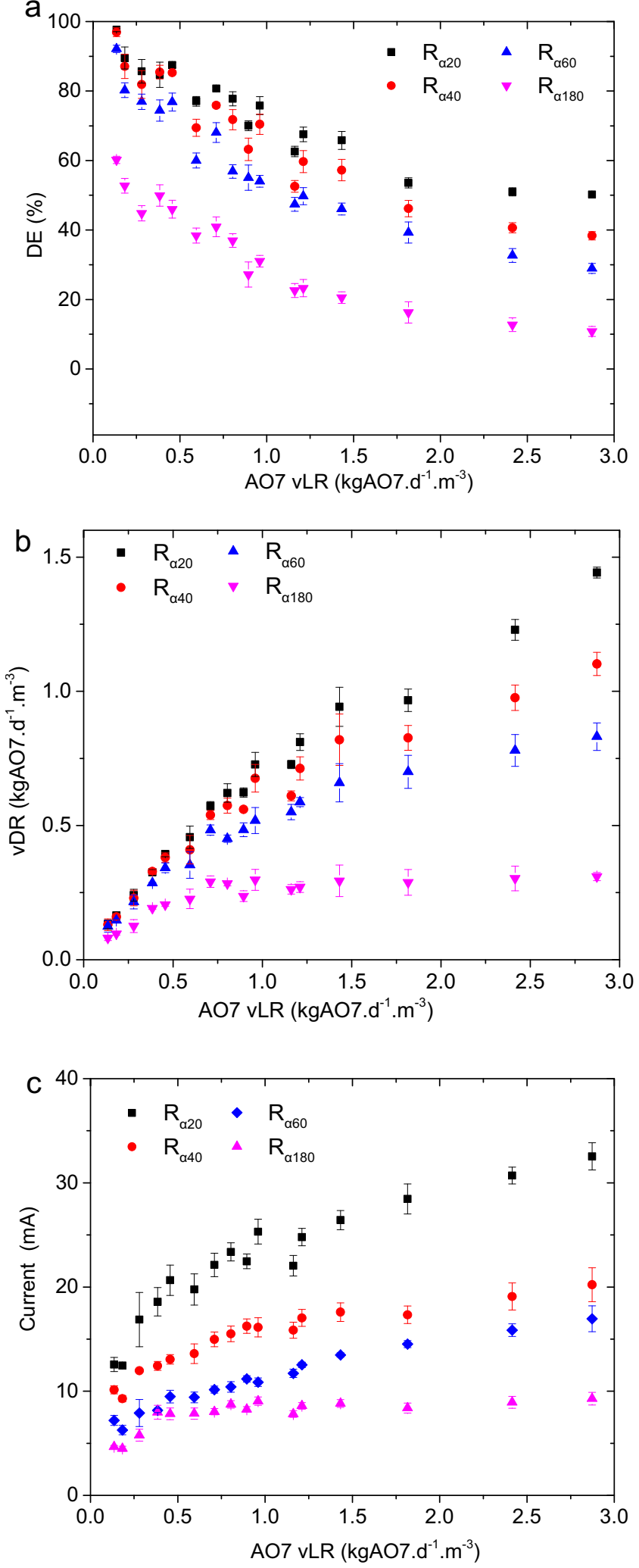

Fig. 3. Effect of $A O 7$ loading rate on (a) decolorization efficiency (DE), (b) volumetric decolorization rates (vDRs), and (c) current generation;.
Table 2

Estimated values of the different parameters for tracer experiments and mLD models at various tHRTs.

\begin{tabular}{lllllll}
\hline tHRT(h) & $\mathrm{v}(\mathrm{m} / \mathrm{h})$ & $\mathrm{R}_{\alpha 20}$ & $\mathrm{R}_{\alpha 40}$ & $\mathrm{R}_{\alpha 60}$ & $\mathrm{R}_{\alpha 180}$ & $\mathrm{R}_{\mathrm{c}}$ \\
\cline { 3 - 6 } & & $\mathrm{MRT}_{\theta}$ & & & & \\
\hline 2 & 0.250 & 1.058 & 1.234 & 1.201 & 0.750 & 0.732 \\
4 & 0.125 & 1.130 & 1.240 & 1.214 & 0.826 & 0.817 \\
6 & 0.083 & 1.142 & 1.361 & 1.209 & 0.876 & 0.816 \\
8 & 0.063 & 1.154 & 1.237 & 1.095 & 0.844 & 0.757 \\
& & & & & & \\
2 & 0.250 & 0.357 & 0.256 & 0.217 & 0.435 & 0.455 \\
4 & 0.125 & 0.345 & 0.345 & 0.323 & 0.476 & 0.370 \\
6 & 0.083 & 0.278 & 0.222 & 0.400 & 0.588 & 0.435 \\
8 & 0.063 & 0.400 & 0.270 & 0.417 & 0.588 & 0.588 \\
& & & & & & \\
2 & 0.250 & 26.054 & 28.733 & 28.438 & 6.251 & 6.432 \\
4 & 0.125 & 20.145 & 21.434 & 39.783 & 6.132 & 6.945 \\
6 & 0.083 & 21.594 & 23.680 & 30.699 & 13.023 & 6.873 \\
8 & 0.063 & 22.224 & 29.769 & 24.469 & 8.650 & 9.297 \\
\hline
\end{tabular}

tHRT represents theoretical HRT, $v$ represents apparent hydraulic up-flow velocity of the reactor, $\mathrm{R}_{\mathrm{c}}$ is the reactor without electrode, $\mathrm{MRT}_{\theta}$ means normalized mean residence time, $\sigma_{\theta}^{2}$ means the square of the standard deviation; $P e_{\mathrm{vfm}}$ means the volume fraction weighted mean Pe values of the mLD model.

the $\mathrm{BES}_{C \text {-SMEM}}, \mathrm{R}_{\alpha 20}$ showed the best decolorization performance. Notably, the maximum enhancement of the vDR in $\mathrm{R}_{\alpha 40}$, compared to $R_{\alpha 180}$, can reach to $255 \%$, although the involved electrode surface area was the same.

The current generations as the function of the AO7 vLRs were shown in Fig. 3c. Similar as the vDRs, the currents of all reactors showed an increase profile. Among all reactors, $R_{\alpha 20}$ always generated the highest current, which was followed by $R_{\alpha 40}, R_{\alpha 60}$ and $R_{\alpha 180}$. This order is in consist with that of vDRs, indicating the decolorization performance was governed by the bioelectrochemical process. In c-SMEM equipped BESs, the various of currents and vDRs can be explained by the different electrode surface area, i.e. the electrode surface area of $R_{\alpha 20}$ was 1.5 times and 2 times higher than that of $R_{\alpha 40}$ and $R_{\alpha 60}$, respectively. However, since the electrode surface area of $R_{\alpha 180}$ was the same as that of $R_{\alpha 40}$, the distinct performance was more likely a result of the difference in configuration (i.e. the planar type and the corrugated type).

\subsection{Hydrodynamics assessment}

The RTD curves of the four BES reactors under different tHRT conditions were shown as in Fig. 4. Regarding to the $p$-SMEM equipped BES, the normalized time $(\theta)$ of the response peak in RTD curves at all tHRT was smaller than one, implying the presence of the dead zones [37]. As the comparison, RTD tests were also perform in an identical reactor but not setting with electrode module $\left(R_{c}\right)$. The corresponding curves were similar as that of the $\mathrm{BES}_{p \text {-SMEM }}$ with almost the same peak $\theta$, suggesting $p$-SMEM has little impact on the hydrodynamics and the status of the dead zones was not improved. In contrast, the $\mathrm{BES}_{c \text {-SMEM }}$ showed an off-set RTD profile featured by longer peak $\theta$. This result clearly indicates the setting of the c-SMEMs could improve the hydrodynamics in the reactors. In addition, the RTD curved can be mathematically featured by two key parameters, the mean residence time $\left(M R T_{\theta}\right)$ and the square of the standard deviation $\left(\sigma_{\theta}^{2}\right)$, which were calculated according to Eqs. (S6) and (S7), respectively, and listed in Table 2. In general, the $\mathrm{BES}_{C \text {-SMEM }}$ had longer $M R T_{\theta}$ and smaller $\sigma_{\theta}^{2}$, indicating the $c$-SMEMs are capable of prolonging the retention time of the tracer and facilitating the flow pattern to be closer to the plug flow reactor (PFR) rather than continuous stirred-tank reactor (CSTR). Moreover, in order to get insight into the flow property, non-ideal flow models were established to stimulate the experimental RTD 


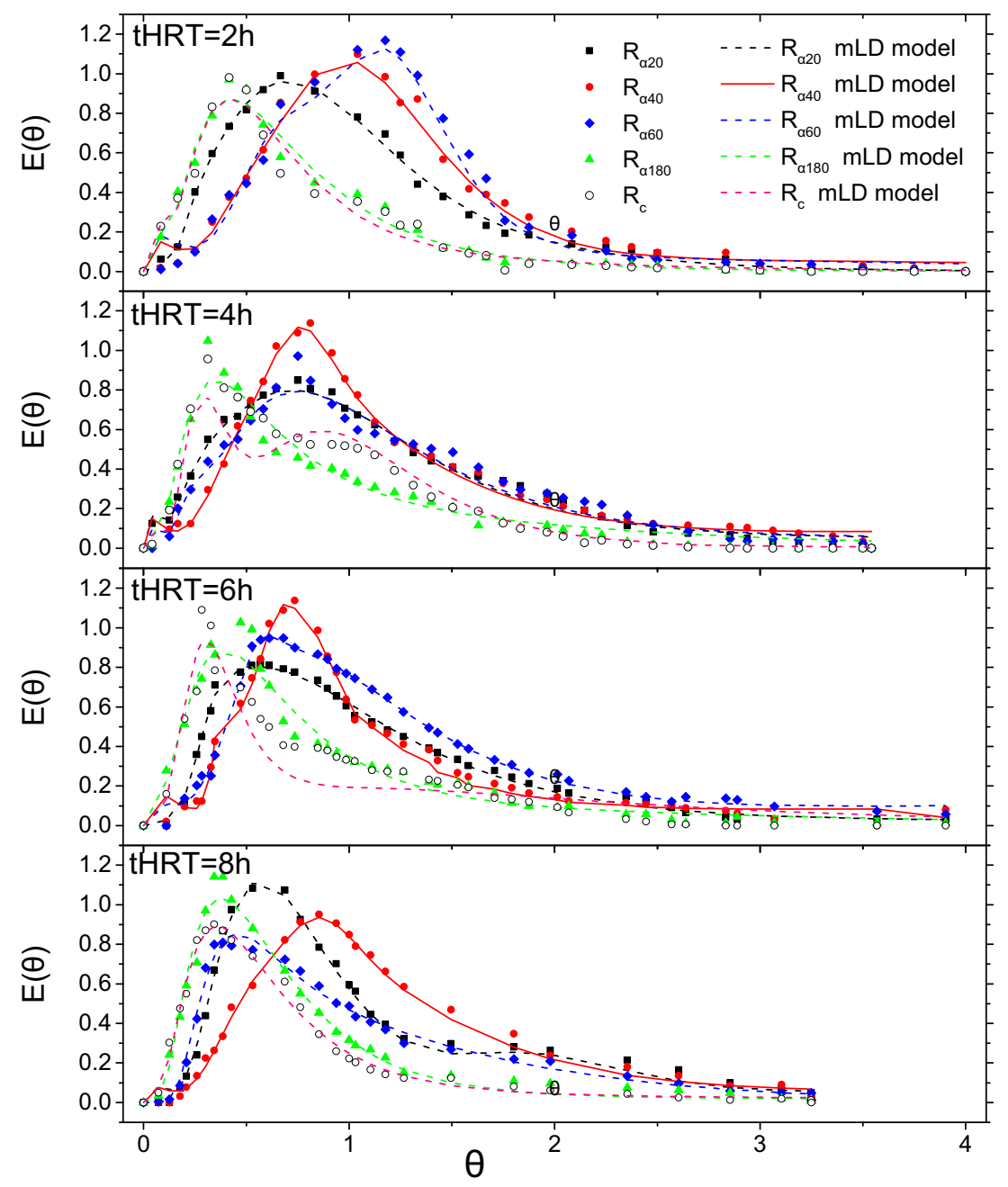

Fig. 4. Different configuration electrode modules' RTD curves and simulation results with modified longitudinal dispersion model;.

curves. As shown in Fig. s1 Fig. s4, the fitting curves generated from the classic TIS model and LD model cannot well match the experimental data. For this, the flow model was modified by treating as the parallel multi-strands [49,50]. Compared to the modified TIS model [50], the modified LD ( $\mathrm{mLD}$ ) model exhibited much better fitting. The peclet $(\mathrm{Pe})$ numbers, representing the ratios of mass transport attributed to advection and dispersion, can be obtained from the mLD model and were listed in Table s2. For comparison, the volume fraction weighted mean $P e$ values $\left(P e_{\mathrm{vfm}}\right)$ from different strands were calculated (Table 2), which indicates the mass transport in $\mathrm{BES}_{c \text {-SMEM }}$ is more inclined to be governed by the advection because of the higher $P e_{\mathrm{vfm}}$.

\section{Discussion}

\section{1. c-SMEM versus $p$-SMEM}

Comparing with the $\mathrm{BES}_{p \text {-SMEM }}, \mathrm{BES}_{c \text {-SMEM }}$ revealed much better performance in terms of greater vDRs, higher current generation, shorter start-up duration and faster biofilm growth. To be noted, $R_{\alpha 40}$ had the same electrode surface area as $R_{\alpha 180 \text {. That means }}$ the performance improvement can be achieved by simply folding the conventional planar electrode as the corrugated type without additional material cost.

As suggested by the hydrodynamics analysis, $c$-SMEM resulted in quite different flow regime in BES. The $M R T_{\theta}$ in $\mathrm{BES}_{c-S M E M}$ was at least 1.47 times higher than that in $\mathrm{BES}_{p \text {-SMEM }}$, indicating $c$ SMEM could prolong the retention time of AO7 in the reactors, which could be one reason to explain the higher vDRs. Notably, $M R T_{\theta}$ in $\mathrm{BES}_{\text {-SMEM }}$ was found to be even over one. This result suggested some eddies may formed in the reactors. Similar results were also reported in the bioelectrochemical system with carbon brush electrode [35] or other bioreactors equipped with different carriers $[51,52]$.

In contrast to the parallel setting of electrodes in $p$-SMEM, electrodes of $c$-SMEM are deployed across the flow direction. As indicated by the bigger $P e_{\mathrm{vfm}}, c$-SMEM likely plays as a barrier that weakened the longitudinal dispersion of AO7. Since the kinetic of AO7 decolorization in BES follows the positive order (usually the first-order) [53,54], the poorer longitudinal dispersion could gain faster apparent reaction rate. In addition, the direction of mass transfer to the electrode surface in $p$-SMEM is vertical to the flow direction, for which the driven force of mass transfer is more governed by the concentration difference between the electrode surface and the bulk solution. Besides the concentration difference, the mass transfer to the electrode surface in $c$-SMEM could be also contributed by the forced convection because the electrodes were set across the flow direction. Thus, the $c$-SMEM may has a faster mass transfer at the surface compared to the $p$-SMEM. Moreover, the deployment of $c$-SMEM forced the fluid flowing through the electrode module. Because the occupancy of stainless-steel wires decreases the flow-through area, the flow velocity in the mesh grids 


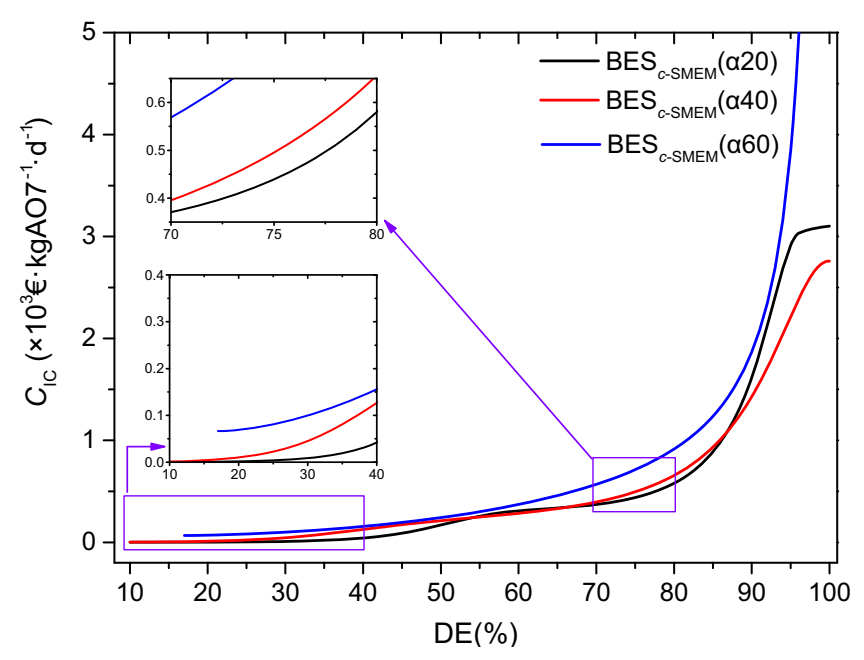

Fig. 5. Initial capital cost of BESs equipped with different $c$-SMEM electrode module based on decolorization efficiency.

could be increased and therefore may further improve the mass transfer. As the mass transfer correlates to the reactions at the electrode surface, it may explain why, compared to the $\mathrm{BES}_{p \text {-SMEM }}$, the higher current, faster biofilm growth and shorter start-up duration were observed in the $\mathrm{BES}_{c \text {-SMEM }}$. A further study based on the computational fluid dynamics (CFD) analysis is warranted, which would help to reveal a clearer difference of the flow regime at these two types of electrode module [55].

\section{2. c-SMEM with different folding angle and techno-economic analysis}

Among the BESs equipped with different type of $c$-SMEM, $R_{\alpha 20}$ achieved the highest DE and vDR, which was followed by the $R_{\alpha 40}$ and then by the $R_{\alpha 60}$ (Fig. 3). However, at the viewpoint of economy, the cost of the electrode module follows the opposite order because the smaller folding angel of the $c$-SMEM requires the larger area of the stainless-steel mesh. Thus, it is necessary to perform a techno-economic analysis that takes both of the decolorization performance and the material cost into account.

Assuming the BESs are fed by the same amount of AO7 per day and have to achieve the same DE, the scale of different $\mathrm{BES}_{C \text {-SMEM }}$ (including the electrode module and the reactor) can be different because of their varied vDRs. According to this principle, the techno-economic assessment model, as following shown, was established to estimate the daily AO7 loads normalized initial capital cost $\left(C_{\mathrm{IC}}, € \mathrm{kgAO7}^{-1} \mathrm{~d}^{-1}\right)$.

$C_{I C}(x)=\left(U_{r e}+U_{\text {ele }}+U_{\text {oth }}\right) / f(x)$

Where, $x$ represents the DE (\%), $f$ is the AO7 vLRs $\left(\mathrm{kgAO}^{-3} \mathrm{~m}^{-1}\right)$ as the function of the DEs (independents variable), which is developed according to Fig. 3a and mathematically treated as Eq. (S18) in $S M$. $U_{\mathrm{re}}$ and $\mathrm{U}_{\text {ele }}$ represent the unit cost of the reactor $\left(€ \mathrm{~m}^{-3}\right)$ and electrode modules $\left(€ \mathrm{~m}^{-3}\right)$, respectively. Since the three types of $c$-SMEM have different extend area, the corresponding $U_{\text {ele }}$ are varied. $U_{\text {oth }}$ represents the other costs involved in the unit electrode module $\left(€ \mathrm{~m}^{-3}\right)$, including current collector, reference electrode and outdoor/industrial data logger. The costs of the electrode module, reactor and the facilities were detailed in Table s1 (SM).

As shown in Fig. 5, $C_{\mathrm{IC}}$ positively correlate to the target DEs. At lower target DEs (<80\%), $C_{\mathrm{IC}}$ slowly increase along with the target DEs, where $\mathrm{R}_{\alpha 20}$ generally has the lowest $C_{\mathrm{IC}}$. Under higher target DEs condition ( $>80 \%), C_{\mathrm{IC}}$ is more sensitive to the target DEs. When the target $\mathrm{DE}$ is over $87 \%, \mathrm{C}_{\mathrm{IC}}$ of $\mathrm{BES}_{\alpha 40}$ becomes lower than that of $\mathrm{R}_{\alpha 20}$. These results suggest that, although the unit cost of $c$-SMEM with smaller folding angle is the higher, the correlated $C_{\mathrm{IC}}$ is not always follow the same rule. When the acceptable AO7 vLRs at certain target DE is enough high in BES with the smaller folding angle of the electrode module, the size of reactor and electrode module can be thereby reduced to balance or even save the $C_{\mathrm{IC}}$. Otherwise, the cost of the unit electrode module would govern the $C_{\mathrm{IC}}$.

Based on the same techno-economic model, $C_{\mathrm{IC}}$ of the conventional anaerobic technologies, such as up-flow anaerobic sludge bed (UASB), anaerobic sequencing batch reactor (ASBR), anaerobic fluidized-bed reactor (AFB) and up-flow constructed wetland (UFCW), were also estimated and compared with that of $\mathrm{BES}_{C \text {-SMEM }}$ at the same target $\mathrm{DE}$ (Table 3). Ostensibly, $C_{\mathrm{IC}}$ is likely higher in BES because of the additional cost of the electrode module. However, as shown in Table 3, $\mathrm{BES}_{\text {-SMEM }}$ shows comparable or even lower $C_{\mathrm{IC}}$. This is mainly because $\mathrm{BES}_{C \text {-SMEM }}$ has higher vDR compared to the conventional technologies (3.3 50 times higher) and therefore results in the cost fed back by reducing the size of the reactor. The comparison of the operation cost for decolorization between $\mathrm{BES}_{C \text {-SMEM }}$ and those conventional technologies is difficult in current stage, because several key parameters to estimate the energy consumption, such as pumping, stirring and heating systems, is not available in the literatures. What can be confirmed is that the additional cost from the external power supply in $\mathrm{BES}_{\text {-SMEM }}$ is not sensitive to the whole operation cost of the wastewater treatment. These concerns as above illuminate the potential of realizing the BESs on wastewater treatment. Additional test to understand the service life of the $c$-SMEM is warranted in future to further strength its application potential, although stainless-steel has been suggested to be stable when carefully controlling the anodic potential especially after the coverage of the anodophilic biofilm [56].

\section{Conclusion}

This work demonstrated the corrugation design of the electrode module was an efficient approach to enhance the decolorization performance in BES. Compared to the conventional p-SMEM, $c$ SMEM equipped BES showed greater DE, higher current generation and shorter startup duration. These improvements were suggested correlating to its contribution on the hydrodynamics, including prolonging the $M R T_{\theta}$ of AO7 and changing the flow pattern closer to the PFR. A techno-economic assessment model was established to elucidate the effects of the decolorization performance and the material cost on the initial capital cost, which served as a tool to understand the most economical configuration of the $c$-SMEM and also revealed the investment of $\mathrm{BES}_{c \text {-SMEM }}$ was comparable or even lower than the traditional bio-decolorization process. The $c$-SMEM is readily industrially structured from the commercial stainless-steel mesh, further highlighting its application potential at large-scale.

\section{Acknowledgments}

We gratefully acknowledge the financial support by the Natural Science Foundation of China (Grant No. 51508551, No. 21577162), the China Postdoctoral Science Foundation(Grand No. 2016T90142, No. 2015M580140), the Ministry of Environmental Protection of the People's Republic of China (Major Science and Technology Program for Water Pollution Control and Treatment, No. 2014ZX07204-005) and the Key Project of Chinese Academy of Sciences (No. ZDRW-ZS2016-5). 


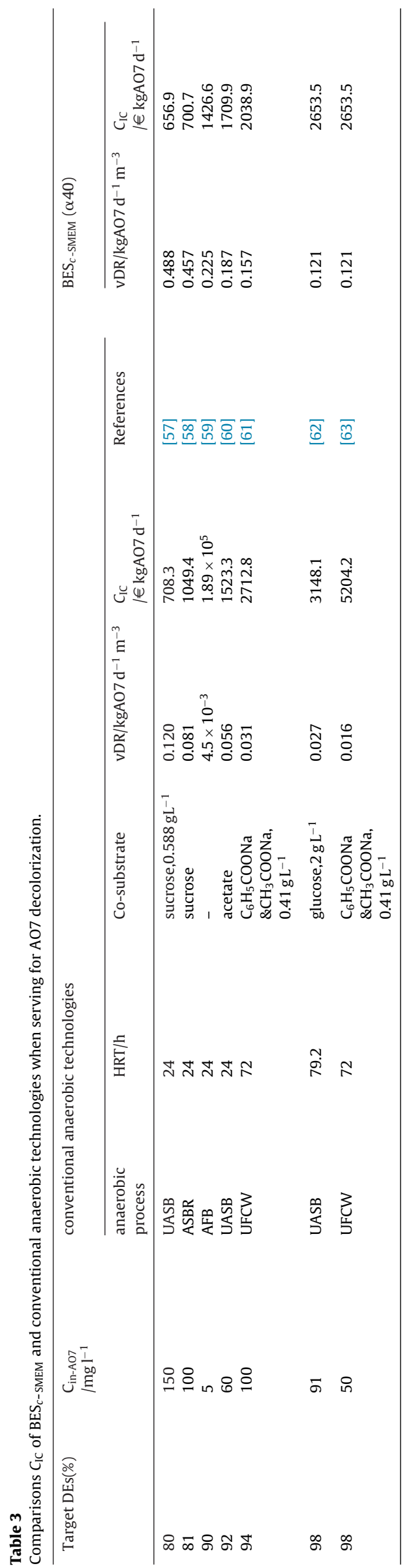

\section{Appendix A. Supplementary data}

Supplementary data associated with this article can be found, in the online version, at http://dx.doi.org/10.1016/j.jhazmat.2017.05. 048 .

\section{References}

[1] B. Logan, R. Hamelers, U. Rozendal, J. Schröder, S.A. Keller, P. Freguia, W.V.A.K. Aelterman, Microbial fuel cells-Methodology and technology, Environ. Sci. Technol. 40 (2006) 5181-5192.

[2] R.A. Rozendal, H.V. Hamelers, K. Rabaey, J. Keller, C.J. Buisman, Towards practical implementation of bioelectrochemical wastewater treatment, Trends Biotechnol. 26 (2008) 450-459.

[3] Y.R. Mu, Korneel Rozendal, A. Rene, Yuan Zhiguo, Keller Jurg, Decolorization of azo dyes in bioelectrochemical process, Environ. Sci. Technol. 43 (2009) 5137-5143.

[4] J. Sun, Z. Bi, B. Hou, Y.Q. Cao, Y.Y. Hu, Further treatment of decolorization liquid of azo dye coupled with increased power production using microbial fuel cell equipped with an aerobic biocathode, Water Res. 45 (2011) 283-291

[5] M.H. Cui, D. Cui, L. Gao, A.J. Wang, H.Y. Cheng, Azo dye decolorization in an up-flow bioelectrochemical reactor with domestic wastewater as a cost-effective yet highly efficient electron donor source, Water Res. 105 (2016) 520-526.

[6] A.-J. Wang, H.-Y. Cheng, B. Liang, N.-Q. Ren, D. Cui, N. Lin, B.H.K.a.K. Rabaey, Efficient reduction of nitrobenzene to aniline with a biocatalyzed cathode, Environ. Sci. Technol. 45 (2011) 10186-10193.

[7] B. Liang, H. Cheng, J.D. Van Nostrand, J. Ma, H. Yu, D. Kong, W. Liu, N. Ren, L. Wu, A. Wang, D.J. Lee, J. Zhou, Microbial community structure and function of nitrobenzene reduction biocathode in response to carbon source switchover, Water Res. 54 (2014) 137-148.

[8] Y.R. Mu, A. Rene, Rabaey Korneel, Keller Jurg, Nitrobenzene removal in bioelectrochemical systems, Environ. Sci. Technol. 43 (2009) 8690-8695.

[9] B. Liang, H.Y. Cheng, D.Y. Kong, S.H. Gao, F. Sun, D. Cui, F.Y. Kong, A.J. Zhou, W.Z. Liu, N.Q. Ren, W.M. Wu, A.J. Wang, D.J. Lee, Accelerated reduction of chlorinated nitroaromatic antibiotic chloramphenicol by biocathode, Environ. Sci. Technol. 47 (2013) 5353-5361.

[10] B.E. Logan, Scaling up microbial fuel cells and other bioelectrochemical systems, Appl. Microbiol. Biotechnol. 85 (2010) 1665-1671.

[11] K. Guo, B.C. Donose, A.H. Soeriyadi, A. Prevoteau, S.A. Patil, S. Freguia, J.J Gooding, K. Rabaey, Flame oxidation of stainless steel felt enhances anodic biofilm formation and current output in bioelectrochemical systems, Environ. Sci. Technol. 48 (2014) 7151-7156.

[12] D. Pant, A. Singh, G. Van Bogaert, S. Irving Olsen, P. Singh Nigam, L. Diels, K. Vanbroekhoven, Bioelectrochemical systems (BES) for sustainable energy production and product recovery from organic wastes and industrial wastewaters, RSC Adv. 2 (2012) 1248-1263.

[13] B.E. Logan, M.J. Wallack, K.-Y. Kim, W. He, Y. Feng, P.E. Saikaly, Assessment of microbial fuel cell configurations and power densities, Environ. Scie. Technol. Lett. 2 (2015) 206-214.

[14] M. Zhou, M. Chi, J. Luo, H. He, T. Jin, An overview of electrode materials in microbial fuel cells, J. Power Sources 196 (2011) 4427-4435.

[15] Y. Feng, Q. Yang, X. Wang, B.E. Logan, Treatment of carbon fiber brush anodes for improving power generation in air?cathode microbial fuel cells, J. Power Sources 195 (2010) 1841-1844.

[16] X.W. Liu, J.J. Chen, Y.X. Huang, X.F. Sun, G.P. Sheng, D.B. Li, L. Xiong, Y.Y. Zhang, F. Zhao, H.Q. Yu, Experimental and theoretical demonstrations for the mechanism behind enhanced microbial electron transfer by CNT network, Sci. Rep. 4 (2014) 3732.

[17] J. Liu, Y. Oiao, C.X. Guo, S. Lim, H. Song, C.M. Li, Graphene/carbon cloth anode for high-performance mediatorless microbial fuel cells, Bioresour. Technol. 114 (2012) 275-280.

[18] J. Zhang. J. Li, D. Ye, X. Zhu, Q Liao, B. Zhang, Enhanced performances of microbial fuel cells using surface-modified carbon cloth anodes: comparative study, Int. J. Hydrogen Energy 39 (2014) 19148-19155.

[19] B.E. Rittmann, Opportunities for renewable bioenergy using microorganisms, Biotechnol. Bioeng. 100 (2008) 203-212.

[20] Y. Yong, X. Dong, M.B. Chan-Park, S. Hao, C. Peng, Macroporous and monolithic anode based on polyaniline hybridized three-Dimensional graphene for high-performance microbial fuel, ACS Nano 6 (2012) 2040-2394.

[21] X. Xie, M. Ye, L. Hu, N. Liu, J.R. McDonough, W. Chen, H.N. Alshareef, C.S Criddle, Y. Cui, Carbon nanotube-coated macroporous sponge for microbial fuel cell electrodes, Energy Environ. Sci. 5 (2012) 5265-5270.

[22] A. Baudler, I. Schmidt, M. Langner, A. Greiner, U. Schröder, Does it have to be carbon? Metal anodes in microbial fuel cells and related bioelectrochemical systems, Energy Environ. Sci. 8 (2015) 2048-2055.

[23] Y.Y. Yu, D.D. Zhai, R.W. Si, J.Z. Sun, X. Liu, Y.C. Yong, Three-Dimensional electrodes for high-Performance bioelectrochemical systems, Int. J. Mol. Sci. 18 (2017).

[24] D.-Z. Sun, Y.-Y. Yu, R.-R. Xie, C.-L. Zhang, Y. Yang, D.-D. Zhai, G. Yang, L. Liu, Y.-C. Yong, In-situ growth of graphene/polyaniline for synergistic improvement of extracellular electron transfer in bioelectrochemical systems, Biosens. Bioelectron. 87 (2017) 195-202. 
[25] D. Massazza, R. Parra, J.P. Busalmen, H.E. Romeo, New ceramic electrodes allow reaching the target current density in bioelectrochemical systems, Energy Environ. Sci. 8 (2015) 2707-2712.

[26] S. Chen, H. Hou, F. Harnisch, S.A. Patil, A.A. Carmona-Martinez, S. Agarwal, Y. Zhang, S. Sinha-Ray, A.L. Yarin, A. Greiner, U. Schröder, Electrospun and solution blown three-dimensional carbon fiber nonwovens for application as electrodes in microbial fuel cells, Energy Environ. Sci. 4 (2011) 1417.

[27] X. Xie, L. Hu, M. Pasta, G.F. Wells, D. Kong, C.S. Criddle, Y. Cui, Three-dimensional carbon nanotube-textile anode for high-performance microbial fuel cells, Nano Lett. 11 (2011) 291-296.

[28] X. Xie, C. Criddle, Y. Cui, Design and fabrication of bioelectrodes for microbial bioelectrochemical systems, Energy Environ. Sci. 8 (2015) 3418-3441.

[29] C. Dumas, A. Mollica, D. Féron, R. Basséguy, L. Etcheverry, A. Bergel, Marine microbial fuel cell: use of stainless steel electrodes as anode and cathode materials, Electrochim. Acta 53 (2007) 468-473.

[30] K. Guo, D. Hidalgo, T. Tommasi, K. Rabaey, Pyrolytic carbon-coated stainless steel felt as a high-performance anode for bioelectrochemical systems, Bioresour. Technol. 211 (2016) 664-668.

[31] D. Pocaznoi, A. Calmet, L. Etcheverry, B. Erable, A. Bergel, Stainless steel is a promising electrode material for anodes of microbial fuel cells, Energy Environ. Sci. 5 (2012) 9645.

[32] S.F. Ketep, A. Bergel, A. Calmet, B. Erable, Stainless steel foam increases the current produced by microbial bioanodes in bioelectrochemical systems, Energy Environ. Sci. 7 (2014) 1633.

[33] S. Zheng, F. Yang, S. Chen, L. Liu, O. Xiong, T. Yu, F. Zhao, U. Schröder, H. Hou, Binder-free carbon black/stainless steel mesh composite electrode for high-performance anode in microbial fuel cells, J. Power Sources 284 (2015) 252-257.

[34] Z. He, F. Mansfeld, Exploring the use of electrochemical impedance spectroscopy (EIS) in microbial fuel cell studies, Energy Environ. Sci. 2 (2009) 215-219.

[35] K.Y. Kim, W. Yang, B.E. Logan, Impact of electrode configurations on retention time and domestic wastewater treatment efficiency using microbial fuel cells, Water Res. 80 (2015) 41-46.

[36] Y. Ahn, M.C. Hatzell, F. Zhang, B.E. Logan, Different electrode configurations to optimize performance of multi-electrode microbial fuel cells for generating power or treating domestic wastewater, J. Power Sources 249 (2014) 440-445.

[37] Y.Z. Wang, Y.K. Wang, C.S. He, H.Y. Yang, G.P. Sheng, J.Y. Shen, Y. Mu, H.Q. Yu, Hydrodynamics of an electrochemical membrane bioreactor, Sci. Rep. 5 (2015) 10387

[38] I.S. Michie, J.R. Kim, R.M. Dinsdale, A.J. Guwy, G.C. Premier, The influence of anodic helical design on fluid flow and bioelectrochemical performance, Bioresour. Technol. 165 (2014) 13-20.

[39] D. Cui, Y.Q. Guo, H.Y. Cheng, B. Liang, F.Y. Kong, H.S. Lee, A.J. Wang, Azo dye removal in a membrane-free up-flow biocatalyzed electrolysis reactor coupled with an aerobic bio-contact oxidation reactor, J. Hazard. Mater. 239-240 (2012) 257-264.

[40] P. Wang, M. Cao, C. Wang, Y. Ao, J. Hou, J. Qian, Kinetics and thermodynamics of adsorption of methylene blue by a magnetic graphene-carbon nanotube composite, Appl. Surf. Sci. 290 (2014) 116-124.

[41] S. Liakou, S. Pavlou, G. Lyberatos, Ozonation of AZO dyes, Water Sci. Technol. 35 (1997) 279-286.

[42] Y.S. Oon, S.A. Ong, L.N. Ho, Y.S. Wong, Y.L. Oon, H.K. Lehl, W.E. Thung, N Nordin, Microbial fuel cell operation using monoazo and diazo dyes as terminal electron acceptor for simultaneous decolourisation and bioelectricity generation, J. Hazard. Mater. 325 (2017) 170-177.

[43] D. Cui, Y.-Q. Guo, H.-S. Lee, H.-Y. Cheng, B. Liang, F.-Y. Kong, Y.-Z. Wang, L.-P. Huang, M.-Y. Xu, A.-J. Wang, Efficient azo dye removal in bioelectrochemical system and post-aerobic bioreactor: optimization and characterization, Chem. Eng. J. 243 (2014) 355-363.
[44] H.C. Wang, H.Y. Cheng, S.S. Wang, D. Cui, J.L. Han, Y.P. Hu, S.G. Su, A.J. Wang, Efficient treatment of azo dye containing wastewater in a hybrid acidogenic bioreactor stimulated by biocatalyzed electrolysis, J. Environ. Sci. (China) 39 (2016) 198-207.

[45] A. Wang, H. Cheng, N. Ren, D. Cui, N. Lin, W. Wu, Sediment microbial fuel cell with floating biocathode for organic removal and energy recovery, Front. Environ. Sci. Eng. 6 (2011) 569-574.

[46] D. Cui, Y.Q. Guo, H.S. Lee, W.M. Wu, B. Liang, A.J. Wang, H.Y. Cheng, Enhanced decolorization of azo dye in a small pilot-scale anaerobic baffled reactor coupled with biocatalyzed electrolysis system (ABR-BES): a design suitable for scaling-up, Bioresour. Technol. 163 (2014) 254-261.

[47] T.U. Nwabueze, M.O. Iwe, Residence time distribution (RTD) in a single screw extrusion of african Breadfruit mixtures, Food Bioprocess Technol. 3 (2008) $135-145$

[48] Y. Zhang, Y. Xiong, Y. Tang, Y. Wang, Degradation of organic pollutants by an integrated photo-Fenton-like catalysis/immersed membrane separation system, J. Hazard. Mater. 244-245 (2013) 758-764.

[49] W.-K. Qi, Y.-L. Guo, M. Xue, Y.-Y. Li, Hydraulic analysis of an upflow sand filter: tracer experiments, mathematical model and CFD computation, Chem. Eng. Sci. 104 (2013) 460-472.

[50] A.J.S.L.J. Burrows, J.R. West, C.F. Forster, A.D. Martin, Evaluation of different analytical methods for tracer studies in aeration lanes of activated sludge plants, Water Res. 2 (1999) 367-374.

[51] P. Munoz, A. Drizo, W. Cully Hession, Flow patterns of dairy wastewater constructed wetlands in a cold climate, Water Res. 40 (2006) 3209-3218.

[52] J.Q. Rebecca Moore, Tom Stephenson, The effects of media size on the performance of biological aerated filters, Water Res. 35 (2001) 2514-2522.

[53] L. Zhang, X. Yin, S.F.Y. Li, Bio-electrochemical degradation of paracetamol in a microbial fuel cell-Fenton system, Chem. Eng. J. 276 (2015) 185-192.

[54] F. Kong, A. Wang, B. Liang, W. Liu, H. Cheng, Improved azo dye decolorization in a modified sleeve-type bioelectrochemical system, Bioresour. Technol. 143 (2013) 669-673.

[55] Q. Ji, D. Yu, G. Zhang, H. Lan, H. Liu, J. Qu, Microfluidic flow through polyaniline supported by lamellar-Structured graphene for mass-Transfer-Enhanced electrocatalytic reduction of hexavalent chromium, Environ. Sci. Technol. 49 (2015) 13534-13541.

[56] K. Guo, A.H. Soeriyadi, H. Feng, A. Prevoteau, S.A. Patil, J.J. Gooding, K. Rabaey, Heat-treated stainless steel felt as scalable anode material for bioelectrochemical systems, Bioresour. Technol. 195 (2015) 46-50.

[57] S.-A. Ong, E. Toorisaka, M. Hirata, T. Hano, Decolorization of azo dye (Orange II) in a sequential UASB?SBR system, Sep. Purif. Technol. 42 (2005) 297-302.

[58] S.-A. Ong, E. Toorisaka, M. Hirata, T. Hano, Decolorization of Orange II using an anaerobic sequencing batch reactor with and without co-substrates, J. Environ. Sci. 24 (2012) 291-296.

[59] S. Seshadri, P.L. Bishop, A.M. Agha, Anaerobic or aerobic treatment of selected azo dyes in wastewater, Waste Manage. 14 (1994)127-137.

[60] R. Bras, A. Gomes, M.I. Ferra, H.M. Pinheiro, I.C. Goncalves, Monoazo and diazo dye decolourisation studies in a methanogenic UASB reactor, J. Biotechnol. 115 (2005) 57-66.

[61] S.A. Ong, K. Uchiyama, D. Inadama, Y. Ishida, K. Yamagiwa, Treatment of azo dye Acid Orange 7 containing wastewater using up-flow constructed wetland with and without supplementary aeration, Bioresour. Technol. 101 (2010) 9049-9057.

[62] D. Mendez-Paz, F. Omil, J.M. Lema, Anaerobic treatment of azo dye Acid Orange 7 under fed-batch and continuous conditions, Water Res. 39 (2005) 771-778.

[63] S.A. Ong, K. Uchiyama, D. Inadama, K. Yamagiwa, Simultaneous removal of color, organic compounds and nutrients in azo dye-containing wastewate using up-flow constructed wetland, J. Hazard. Mater. 165 (2009) 696-703. 